\title{
Efecto de un concentrado autólogo de plaquetas en colgajos cutáneos en conejos
}

\author{
Effect of platelet-rich plasma on skin flaps in rabbits
}

Catherine Aragón-Urrego ${ }^{1}$, Irma Ximena Barbosa ${ }^{2}$, Omar Leonardo Aristizabal ${ }^{2,3}$

\section{Resumen}

El concentrado autólogo de plaquetas (CAP) ha sido utilizado como acelerador de la cicatrización cutánea en medicina veterinaria. El objetivo del presente trabajo fue evaluar el efecto de un CAP en colgajos cutáneos en conejos (Oryctolagus cuniculus). Se utilizaron 10 conejos machos Nueva Zelanda divididos aleatoriamente en un grupo control y un grupo CAP. Se hizo un colgajo cutáneo de rotación en la región toraco-dorsal del miembro torácico derecho de los conejos. La mitad de los conejos recibieron CAP infiltrado bajo el colgajo. Se tomaron biopsias de la unión del colgajo con el lecho receptor a los $3,7,14$ y 21 días posquirúrgico. Se hizo el análisis histológico del infiltrado inflamatorio y se determinó la proliferación de fibroblastos y tipo de colágeno formado. Se observó diferencia significativa en el recuento de neutrófilos, macrófagos y fibroblastos. El análisis histológico demostró que una única aplicación de CAP no reduce el tiempo de cicatrización en colgajos cutáneos; sin embargo, promueve la formación de vasos sanguíneos y reduce el infiltrado inflamatorio en conejos a lo largo del tiempo experimental.

Palabras clave: conejo; concentrado autólogo de plaquetas; colgajo cutáneo; cicatrización de heridas

\section{Abstract}

Autologous platelet concentrates (APC) has been used as an accelerator of cutaneous healing in veterinary medicine. The aim of this study was to evaluate the effect of an APC on skin flaps in rabbits (Oryctolagus cuniculus). Ten New Zealand male rabbits were randomly divided into a control group and an APC group. A rotating cutaneous flap was

${ }^{1}$ Facultad de Medicina Veterinaria y Zootecnia, Universidad del Tolima, Ibagué, Colombia

${ }^{2}$ Grupo de Investigación en Medicina y Cirugía de Pequeños Animales, Facultad de Medicina Veterinaria y Zootecnia, Universidad del Tolima, Ibagué, Tolima, Colombia

${ }^{3}$ E-mail: olaristizabalp@ut.edu.co

Recibido: 3 de abril de 2018

Aceptado para publicación: 27 de septiembre de 2018 
made in the thoraco-dorsal region of the right thoracic limb of the rabbits. Half of the rabbits received APC infiltrated under the flap. Biopsies were taken from the union of the flap with the recipient bed at 3, 7, 14, and 21 days post-surgery. The histological analysis of the inflammatory infiltrate was made, and the proliferation of fibroblasts and type of collagen formed was determined. A significant difference was observed in the neutrophil count, macrophages and fibroblasts. The histological analysis showed that a single application of CAP does not reduce the healing time in skin flaps; however, it promotes the formation of blood vessels and reduces the inflammatory infiltrate in rabbits throughout experimental time.

Key words: rabbit; autologous platelets concentrate; skin flap; wound healing

\section{INTRODUCCIÓN}

El proceso de reparación tisular comprende la interacción de células sanguíneas, factores de crecimiento, citoquinas y componentes de la matriz extracelular durante las fases de inflamación, proliferación y remodelación que culminan con la restauración del tejido afectado (João De Masi et al., 2016). La cicatrización por primera intención es el método de elección para reparar una herida limpia confrontando los bordes del defecto por medio de sutura (Brodland, 1994; Jensen et al., 2008). Las lesiones contaminadas requieren métodos más complejos de cierre, como la cicatrización por segunda intención. La herida se contrae por acción de los miofibroblastos y se reepitaliza desde la periferia (Sterne y Fatah, 2002). Sin embargo, los defectos de gran tamaño en los que no es posible reparar adecuadamente por primera o segunda intención, han propiciado el desarrollo de procedimientos quirúrgicos que permitan devolver la apariencia de la piel de la forma más estética posible.

Los colgajos cutáneos son bloques de tejidos conformados por epidermis, dermis y tejido subcutáneo (Coll, 2016), con un pedículo, el cual garantiza la irrigación del colgajo al presentar una arteria o vena en el tejido elevado (Schultz et al., 2014). La elección del tipo de colgajo dependerá, entre otros factores, de la localización del defecto, tejido disponible adyacente a la lesión y a su irrigación sanguínea (Le Cocq y Stanley, 2011). Sin embargo, cuando el aporte sanguíneo del pedículo es escaso o la formación de nuevos vasos sanguíneos es insuficiente, se puede dar lugar a procesos de necrosis parcial o total (Trevor et al., 1992; Amsellem, 2011).

El concentrado autólogo de plaquetas (CAP), un hemoderivado obtenido a partir de la centrifugación de la sangre con anticoagulante, combina las plaquetas y las proteínas plasmáticas en cantidades suprafisiológicas para favorecer la cicatrización cutánea y la reparación de los tejidos en el lugar de aplicación (Burnouf et al., 2013). Las plaquetas contienen mediadores biológicos en sus gránulos $\alpha$ conocidos como factores de crecimiento, los cuales tienen la capacidad de mejorar la regeneración de tejidos óseos y blandos; además de tener efectos benéficos en el tratamiento de heridas crónicas (Eppley et al., 2004; Kim et al., 2007; Sun et al., 2007; Wang et al., 2016).

El conejo, como modelo experimental, es preferido por su fácil consecución y mantenimiento. Debido a sus características tegumentarias, como por ejemplo, el grosor de la dermis de la región toracodorsal, proporciona una amplia zona para crear defectos de gran tamaño (Da Costa Gonçalves et al., 2007). El presente estudio tuvo como objetivo evaluar el proceso de reparación de colgajos cutáneos de rotación en un modelo 
lagomorfo, tratados con un concentrado autólogo de plaquetas, determinando por medio de análisis histológico y morfométrico la respuesta inflamatoria y la formación de colágeno.

\section{Materiales y Métodos}

\section{Modelo Experimental}

Diez conejos (Oryctolagus cuniculus) machos Nueva Zelanda, con peso vivo entre 2.5 y $3.5 \mathrm{~kg}$, y de condición clínica favorable, fueron utilizados como modelo experimental. Todos los conejos fueron alojados en un ambiente libre de patógenos, alimentados con concentrado comercial (17\% de proteína; Solla, Colombia) y agua ad libitum. El presente estudio fue aprobado por el Comité de Ética para Experimentación Animal de la Universidad del Tolima (Acta N. ${ }^{\circ}$ 2, mayo de 2017).

\section{Concentrado Autólogo de Plaquetas (CAP)}

Los animales fueron pre-medicados con cefalexina $25 \mathrm{mg} / \mathrm{kg}$ y meloxicam $0.2 \mathrm{mg} / \mathrm{kg}$ vía intramuscular $30 \mathrm{~min}$ antes del procedimiento quirúrgico. La anestesia fue inducida con xilacina $2 \mathrm{mg} / \mathrm{kg}$ y ketamina $6 \mathrm{mg} / \mathrm{kg}$ vía intravenosa. Siguiendo la metodología descrita en Bonilla et al. (2017), $2 \mathrm{ml}$ de lidocaína al $2 \%$ fueron infiltrados en el tejido subcutáneo adyacente a la vena yugular. Se hizo una incisión longitudinal en la piel a nivel del surco yugular, el músculo cutáneo del cuello fue incidido y desplazado lateralmente, permitiendo la visualización de la vena yugular externa. Se colectó sangre por medio de dos tubos vacutainer de $3.5 \mathrm{ml}$ cada uno, estériles, con citrato de sodio al $3.2 \%$ como anticoagulante (VACUETTE® Greiner-Bio-One, Austria) (Figura 1).

La sangre de uno de los tubos fue utilizada para realizar hemograma rutinario (analizador automatizado de hematología FC-620

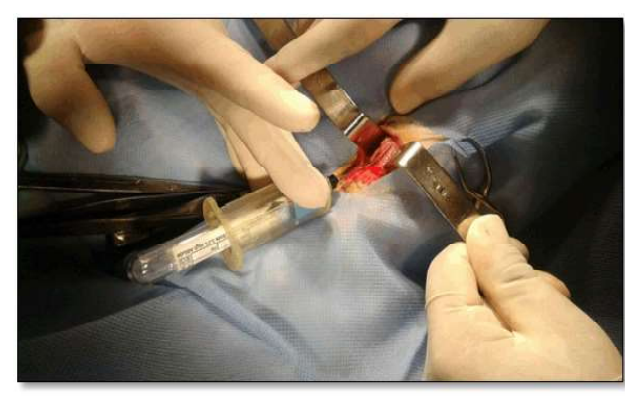

Figura 1. Venodisección y colecta de sangre

Vet, Fuerte Care, Colombia), con la finalidad de obtener los niveles basales de todas las líneas celulares. Los dos tubos fueron sometidos a un ciclo de centrifugación (Centrifuga Z32HK, Hermle ${ }^{\circledR}$ Labortechnik GmbH, Alemania) a $120 \mathrm{~g}$ durante $5 \mathrm{~min}$ para lograr la separación de los tres componentes sanguíneos. Por medio de un catéter N. ${ }^{\circ} 24$ (Safelet, Nipro, Colombia) fue colectado $1 \mathrm{ml}$ de la porción inmediatamente superior a la capa leucocitaria de cada tubo (plasma). el cual fue almacenado en un tubo sin anticoagulante (Vacuette ${ }^{\circledR}$ Greiner-Bio-One, Austria), para posteriormente ser analizado en el equipo de hematología y verificar la concentración de plaquetas obtenidas.

\section{Creación del Colgajo Cutáneo}

El área toraco-dorsal del miembro torácico derecho fue rasurado. El procedimiento quirúrgico fue realizado bajo condiciones asépticas. Las zonas por incidir fueron infiltradas con $2 \mathrm{ml}$ de lidocaína al $2 \%$. Se obtuvo un colgajo de rotación rectangular de $5 \times 3 \mathrm{~cm}$. El defecto fue visualizado como un cuadrado de $3 \mathrm{~cm}$ ubicado $4 \mathrm{~cm}$ caudal al acromion. Una vez rotado el colgajo sobre la lesión fue suturado con hilo de polipropileno (Prolene ${ }^{\circledR}$ Ethicon, Johnson \& Johnson) 3/0 en puntos simples separados (Figura 2).

Los conejos fueron divididos al azar en dos grupos. El grupo control (GC) fue suturado con polipropileno únicamente. Al grupo tratado (GCAP) se le infiltró bajo el colgajo 2 
$\mathrm{ml}$ de CAP previa activación con gluconato de calcio (Vicar Farmacéutica, Colombia) en proporción 1:10 (0.2 $\mathrm{ml}$ de gluconato de calcio por cada $2 \mathrm{ml}$ de CAP). El tratamiento posquirúrgico incluyó la administración de antibiótico (cefalexina $25 \mathrm{mg} / \mathrm{kg}$ ) durante siete días y antiinflamatorio (meloxicam $0.2 \mathrm{mg} / \mathrm{kg}$ ) durante tres días vía intramuscular.

\section{Análisis Histológico y Morfométrico}

Biopsias de piel de la unión del colgajo al lecho receptor fueron obtenidas por medio de un punch (BP 80F 8mm, Kai Medical ${ }^{\circledR}$, Alemania) de $8 \mathrm{~mm}$ a los 3, 7, 14 y 21 días después de la cirugía. Las muestras fueron fijadas en formalina $10 \%$ tamponada, deshidratadas e incluidas en parafina para el estudio histopatológico. Las secciones de tejido fueron coloreadas con hematoxilinaeosina para evaluar el infiltrado inflamatorio (neutrófilos, macrófagos y linfocitos) y proliferación de fibroblastos. El número mínimo de campos fue determinado utilizando la metodología descrita en Moro et al. (2004). La síntesis de colágeno fue evaluada en secciones de tejido teñidas con tricrómico de Masson. Las fotomicrografías fueron obtenidas con cámara digital (Olympus XC50) en microscopio trinocular invertido modular (IX73P2F, Japón) visualizando los tejidos por medio del programa CellSens Estándar v. 1.12 (Olympus ${ }^{\circledR}$, Japón). El tipo de colágeno fue determinado en los tejidos coloreados con PicroSirius rojo observados en microscopio de luz polarizada (Olympus BX51, Japón).

\section{Análisis Estadístico}

Los resultados fueron presentados como media \pm desviación estándar. Se realizó la prueba de normalidad de Kolmogorov Smirnov a todos los valores de cada variable. Los recuentos de plaquetas en las muestras sanguíneas pre- y pos-centrifugación fueron analizados mediante prueba de Wilcoxon. Las diferencias entre los grupos fueron evaluadas utilizando la prueba $\mathrm{U}$ de
Mann-Whitney. Se consideró significativo un valor de $\mathrm{p}<0.05$. Los datos fueron analizados utilizando el programa GraphPad Prism v. 6 (La Jolla, CA, EEUU).

\section{Resultados}

\section{Concentrado Autólogo de Plaquetas (CAP)}

El recuento de plaquetas entre antes $\left(149.0 \pm 68.2 \times 10^{9} / \mathrm{L}\right)$ y después del proceso de centrifugación $\left(244.4 \pm 96.5 \times 10^{9} / 1\right)$ no presentó diferencia significativa $(\mathrm{p}=0.06)$. Sin embargo, se evidenció un ligero aumento entre las medias en el concentrado plaquetario comparado con la sangre entera.

\section{Análisis Histológico}

En los colgajos de los dos grupos se observó pérdida de continuidad epitelial y formación de coágulo característico con hilos de fibrina e infiltrado de células sanguíneas blancas, compuestas principalmente por polimorfonucleares neutrófilos. Al $3^{\text {er }}$ día de la cirugía se observó angiogénesis moderada en la dermis en GC y acentuada en GCAP. La zona de transición entre los tejidos donante y receptor se observó claramente en los dos grupos, siendo evidente una organización más temprana de reparación en el GCAP con aparición de tejido de granulación activo, menor infiltrado celular y presencia moderada de fibroblastos siete días después de la cirugía. En el día 14 de la cirugía se observó tejido conectivo denso con moderada celularidad de fibroblastos y menor presencia de vasos sanguíneos en los animales del GCAP. Así mismo, 21 días después de la cirugía se observó epitelio fino y paralelo, disminución del infiltrado leucocitario con mejor integración del lecho donante y receptor, así como fibras colágenas más homogéneas y perpendiculares a la epidermis en el GCAP. Las papilas dérmicas fueron más acentuadas en GC (Figura 3A-B). 


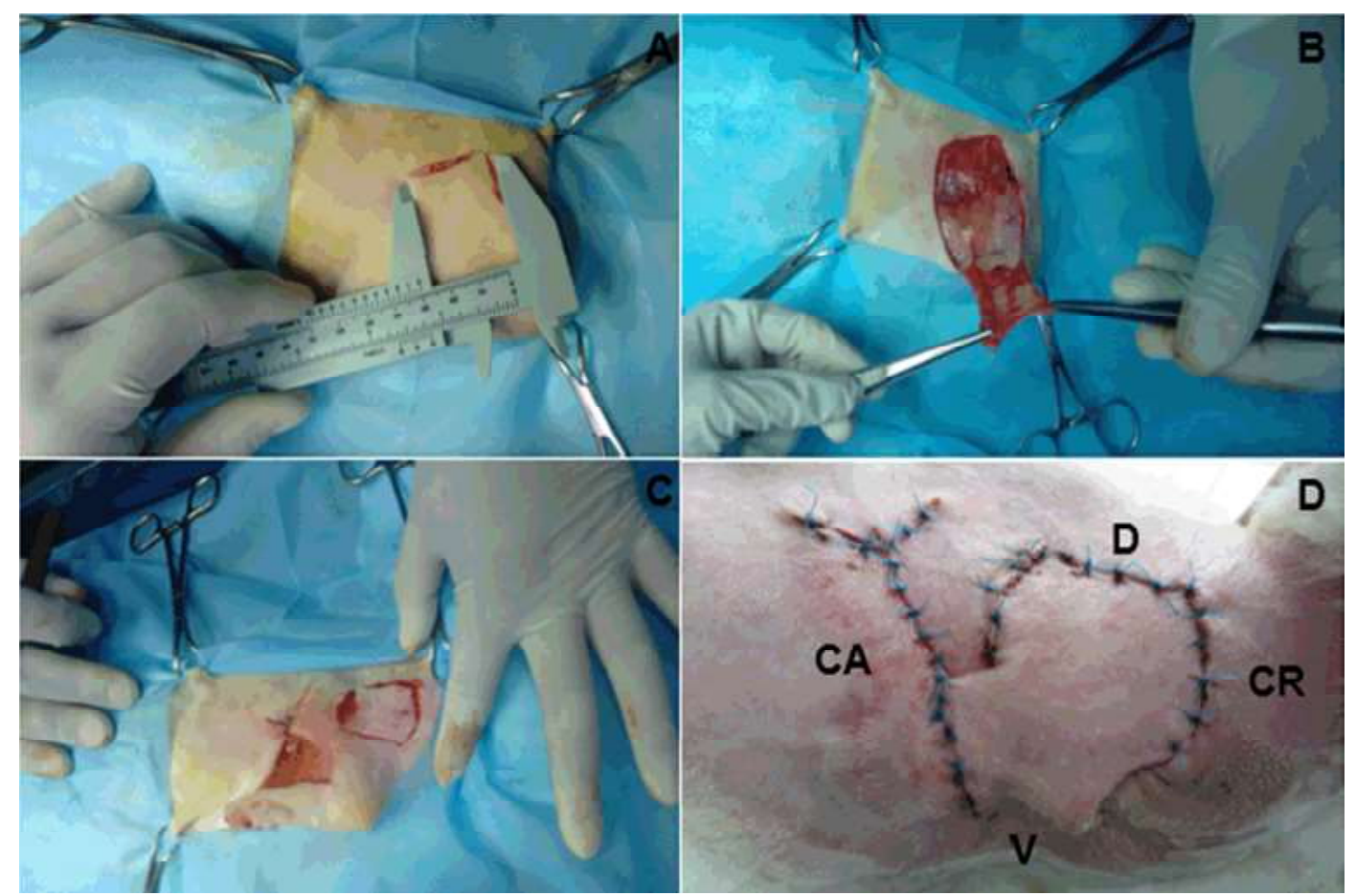

Figura 2. Creación del colgajo cutáneo A. Creación del defecto. B. Elevación del colgajo. C. Visualización del colgajo y defecto. D. Colgajo cutáneo de rotación (D: dorsal, V: ventral, CR: craneal, CA: caudal)

\section{Infiltrado Inflamatorio}

La reacción inflamatoria fue determinada por el número de leucocitos, específicamente mediante la subpoblación de macrófagos, neutrófilos y linfocitos presentes en los días 3, 7, 14 y 21 posquirúrgico (Figura 4). Se observó diferencia significativa en el recuento de macrófagos a los 21 días $(\mathrm{p}=0.01)$ y neutrófilos al día $7(\mathrm{p}=0.01)$ posquirúrgico. No se observó diferencia significativa en el recuento de linfocitos en ninguno de los tiempos experimentales.

\section{Proliferación de Fibroblastos}

El recuento de fibroblastos en el día 14 posquirúrgico del GCAP $(49.84 \pm 12.01)$ fue significativamente mayor comparado con GC $(27.84 \pm 15.31)(\mathrm{p}=0.03)$ (Figura 5). Al evaluarse la proliferación de fibroblastos entre GC y GCAP en los días 3, 7 y 21 posquirúrgico, GCAP presentó medianas mayores.

\section{Tricrómico de Masson}

Los análisis histológicos mostraron formación de coágulo y vasos sanguíneos con marcado infiltrado inflamatorio en GC al $3^{\text {er }}$ día posquirúrgico. Fibras de colágeno coloreadas intensamente en verde fueron observadas en el tejido conjuntivo irregular, siendo evidente la intersección entre el tejido preformado y el tejido en formación en GC y GCAP siete días después de la cirugía. Un proceso de regeneración en la zona de transición del colgajo, con presencia de fibras colágenas laxas y densas fueron evidentes en GC y GCAP en el día 14. Así mismo, presencia de anexos cutáneos y tejido conjuntivo más organizado con fibras moderadamente densas fueron observadas en GCAP, mientras que infiltrado inflamatorio subepidérmico moderado y edema dérmico fueron evidentes en GC (Figura 3 C-D). 

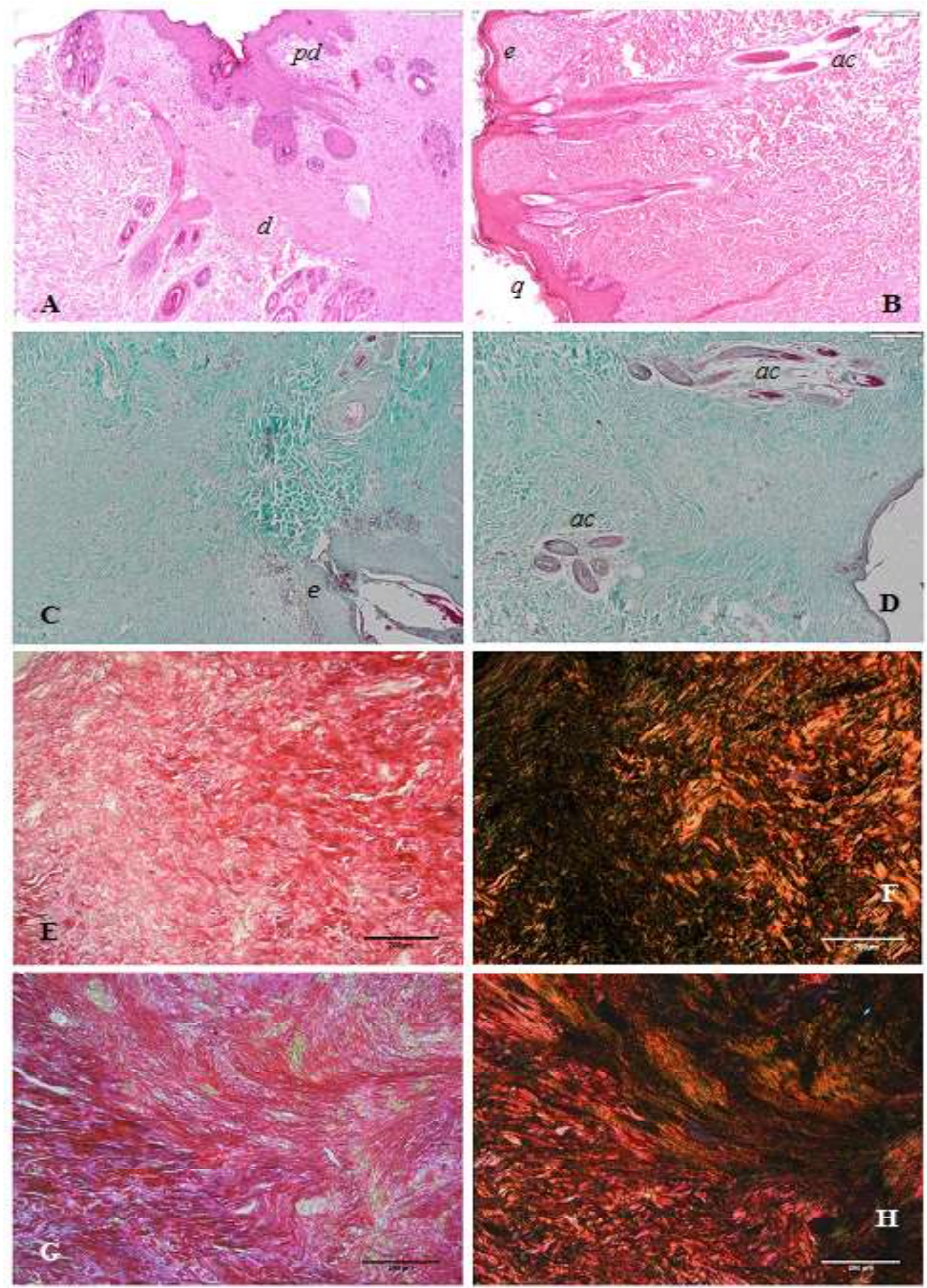

Figura 3. Imágenes representativas de colgajo cutáneo de conejos a los 21 días de la cirugía en tinción H-E, 10x (A: grupo control [GC], B: grupo concentrado autólogo de plaquetas [CAP]). Se observa presencia de papilas dérmicas $(p d)$ y anexos cutáneos $(a c)$, tanto en (A) como en (B). (q) queratina, (d) dermis. Tricrómico de Masson, 10x (C; GC; D; CAP). En (C) se observa una epidermis (e) más gruesa (entre 9 y 12 estratos epidérmicos) e irregular que en (D). PicroSirius rojo, 10x. (E: GC; G: CAP, luz directa; F: GC, H: CAP en luz polarizada). Birrefringencia rojoamarilla colágeno tipo I; birrefringencia verde colágeno tipo III. No se observa predominio de un tipo u otro de fibra colágena 

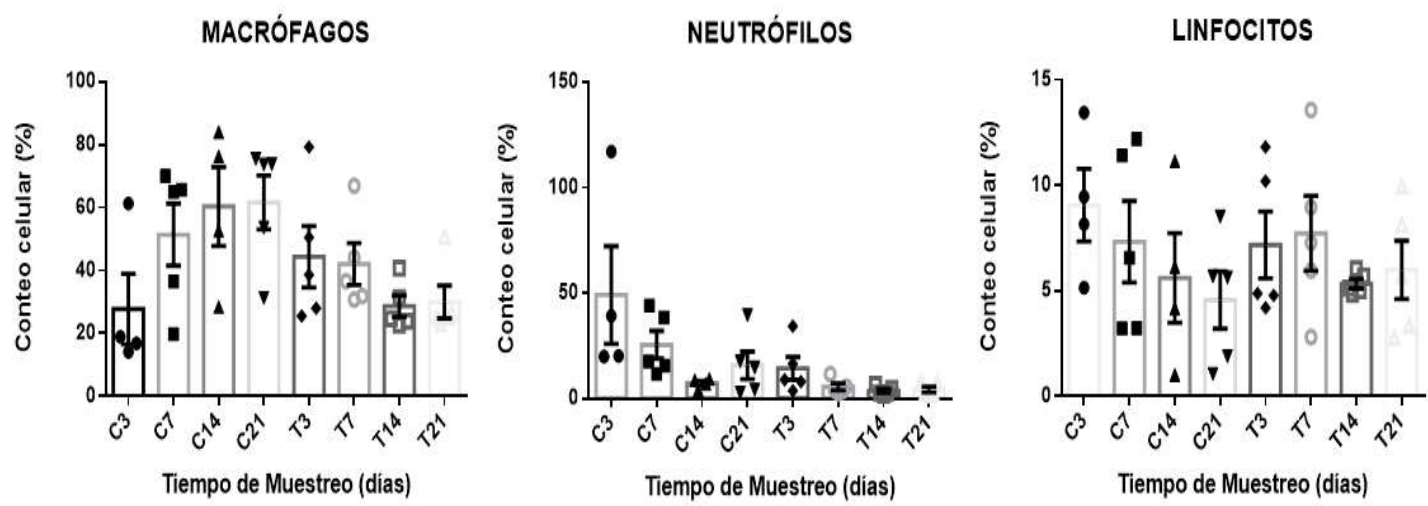

Figura 4. Efecto del Concentrado Autologo de Plaquetas (CAP) en colgajos cutáneos en conejos. Recuento del infiltrado inflamatorio en el grupo control (C) y grupo tratado (T) durante 21 días posteriores a la cirugía

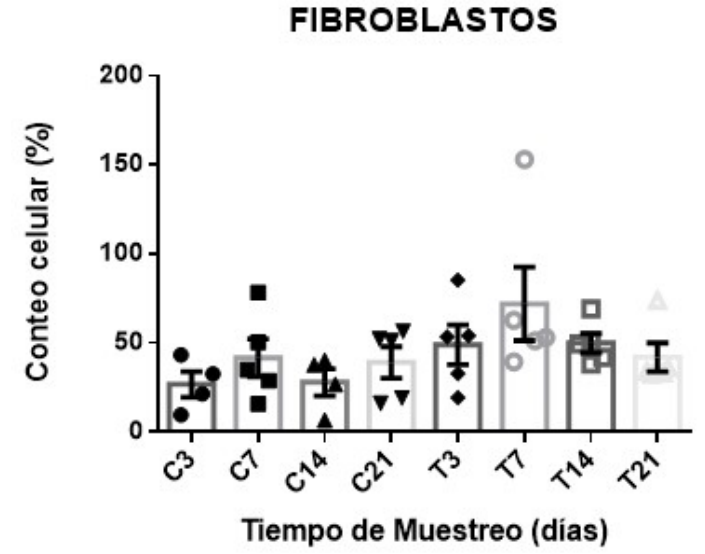

Figura 5. Efecto del Concentrado Autologo de Plaquetas (CAP) en colgajos cutáneos en conejos. Recuento de la proliferación fibroblástica en el grupo control (C) y grupo tratado $(\mathrm{T})$ durante 21 días posteriores a la cirugía

\section{Colágeno con Tinción PicroSirius}

En las figuras $3 \mathrm{E}$ y $3 \mathrm{G}$ se observa la coloración rojiza y amarillenta en la dermis, no pudiéndose diferenciar claramente los colágenos tipo I y III de la matriz extracelular. La dermis en la Figura 3F muestra birre- fringencia naranja y rojiza, debido a la presencia de colágeno Tipo I, con áreas de birrefringencia verde-amarillo verdoso (colágeno tipo III). En la Figura 3H se observa colágeno Tipo I, con birrefringencia naranja y rojiza en el tejido receptor y similar distribución de colágeno tipo I y tipo III (birrefringencia verdoso-amarillenta) en haces semi-arremolinados que tienden a formar una matriz con haces paralelos en la zona de regeneración del colgajo (tejido cicatricial). Se nota que las fibras tienden a presentar una disposición en «zig-zag», mostrando fibras colágenas tipo III en haces entrelazados.

\section{Discusión}

Los colgajos cutáneos representan la mejor opción para reestablecer la integridad de una lesión de gran tamaño. La irrigación y la longitud de los colgajos son factores fundamentales para tener en consideración antes y durante el procedimiento quirúrgico. El presente estudio demostró que una rama cutánea de la arteria subescapular garantizó el aporte sanguíneo de colgajos toraco-dorsales de tamaño pequeño tratados o no con plasma rico en plaquetas (CAP), evitando la presentación de alteraciones relacionadas con 
la irrigación. Pazzini et al. (2016) reportaron el uso de la arteria y vena toraco-dorsal en colgajos de patrón axial suturados en el codo en conejos. En su estudio, los autores evidenciaron necrosis en la porción distal de los tejidos causado posiblemente por la obliteración del vaso sanguíneo en el pedículo, impidiendo una perfusión adecuada al tejido movilizado, dando lugar a procesos de isquemia (Lucas, 2017). Por su parte, Wang et al. (2016) demostraron que el CAP acelera el proceso de neoangiogénesis en colgajos de patrón aleatorio, similar a lo hallado en este trabajo, donde la angiogénesis temprana fue más acentuada en los animales tratados con CAP.

El estudio histológico demostró marcado infiltrado inflamatorio en las etapas iniciales, disminuyendo a lo largo del tiempo experimental en el grupo control. Lo anterior coincide con los resultados del análisis morfométrico evidenciando mayor infiltración celular, principalmente de tipo polimorfonuclear, en GC comparado con GCAP. Estos hallazgos son similares a los reportados en Bonilla (2016), al observar recuentos mayores de neutrófilos en heridas dérmicas en conejos 3 y 7 días después de realizada la lesión. En colgajos de patrón aleatorio tratados con CAP, Wang et al. (2016) cuantificaron menor cantidad de células inflamatorias en muestras colectadas 3 y 7 días después de la intervención quirúrgica. Se ha descrito que las plaquetas producen el factor de crecimiento de hepatocitos (HGF), un factor pleiotrópico que inhibe la función del factor de transcripción nuclear kappa beta (NF- $\kappa \beta)$, principal regulador del proceso inflamatorio (Bendinelli et al., 2010; Boswell et al., 2012).

El infiltrado mononuclear aumentó gradualmente a lo largo del tiempo experimental, siendo mayor el conteo en el grupo control 21 días después de la cirugía. Es bien conocido que después de la fase inflamatoria, la línea celular predominante son los macrófagos (Meszaros et al., 1999; Brancato y Albina, 2011), que al ser activados por mediadores inflamatorios liberados en el lugar de la lesión (Zhang y Mosser, 2008; Koh y DiPietro, 2011), producen el factor de crecimiento transformante-beta (TGF- $\beta$ ), el cual puede promover la infiltración de los fibroblastos, la quimiotaxis de células inflamatorias y el depósito de colágeno en el área afectada (Martin y Leibovich, 2005; Mahdavian Delavary et al., 2011). Los resultados del recuento de células linfocíticas fueron mayores 3 y 7 días después del procedimiento quirúrgico, lo cual coincide con la infiltración de linfocitos T en la fase tardía de la inflamación por acción de la IL-1, llegando a su punto más alto siete días después de ocurrida la lesión (Portou et al., 2015).

La cicatrización de las lesiones cutáneas está regulada principalmente por la acción de los fibroblastos, promoviendo la formación de matriz extracelular (Madden y Peacock, 1971; Reinke y Sorg, 2012). La evaluación histológica de las microfotografías permitió observar una mayor concentración de fibroblastos en el grupo CAP, principalmente en el día 14 posquirúrgico, mostrando fibras de colágeno densas en la dermis reticular en las etapas finales del proceso de reparación. Resultados similares reportaron Bertone et al. (2016) al evidenciar proliferación significativa de fibroblastos 15 y 30 días posquirúrgico en colgajos de avance tratados con plasma rico en factores de crecimiento.

Se ha demostrado que los derivados hemáticos como el CAP pueden promover la formación de colágeno, especialmente tipo I y tipo III a través de la expresión del gen de la proteína de matriz del fibroblasto (Xian et al., 2015). En este estudio, los tejidos coloreados con PicroSirius rojo y observados bajo polares cruzados mostraron birrefringencia mixta en los grupos experimentales, siendo difícil determinar el predominio de colágeno tipo I o tipo III. Durante el proceso de cicatrización el colágeno tipo III se produce rápidamente para formar una barrera de fibras delgadas y débiles en el área de la lesión (Gurtner et al., 2008; Wong et al., 2013), el cual es degradado por las proteasas producidas por los fibroblastos para formar colágeno 
tipo I que proporciona una mayor resistencia a los tejidos (Witte y Barbul, 1997; Bainbridge, 2013).

\section{Conclusiones}

- La aplicación de concentrado autólogo de plaquetas (CAP) con bajas concentraciones de plaquetas promovió la formación de vasos sanguíneos, redujo el infiltrado inflamatorio y estimuló la proliferación de fibroblastos con la consecuente formación de fibras de colágeno en colgajos de rotación en conejos.

- Los hallazgos microscópicos indican que la aplicación de un hemoderivado como el CAP podría acelerar la regeneración de tejidos en pacientes sometidos a cirugía reconstructiva.

\section{Literatura Citada}

1. Amsellem P. 2011. Complications of reconstructive surgery in companion animals. Vet Clin N Am-Small 41: 9951006. doi: 10.1016/j.cvsm.2011.05.005

2. Bainbridge P. 2013. Wound healing and the role of fibroblasts. J Wound Care 22: 407-412. doi: 10.12968/jowc.2013.22.8.407

3. Bendinelli P, Matteucci E, Dogliotti G, Corsi MM, Banfi G, Maroni P, Desiderio MA. 2010. Molecular basis of anti-inflammatory action of plateletrich plasma on human chondrocytes: mechanisms of NF-kappaB inhibition via HGF. J Cell Physiol 225: 757-766. oi: 10.1002/jcp.22274

4. Bertone P, Wheeler J, Romanini M, Boaglio C, Ruiz F, Suárez A, Aramayo A, Torrretta M. 2016. Análisis histológico del efecto de plasma rico en factores de crecimiento (prfc) en la cicatrización de piel en conejos. En: Convención Internacional Virtual de Ciencias Morfológicas. Cuba.
5. Bonilla A. 2016. Uso de concentrado autólogo de plaquetas como terapia regenerativa post quirúrgica en heridas dérmicas en conejos (Oryctolagus cuniculus). Tesis de Médico Veterinario Zootecnista. Ibagué: Univ del Tolima. 32 p.

6. Bonilla-Gutiérrez AF, Aragón-Urrego C, Aristizabal-Páez O. 2017. Protocolo para la obtención de un concentrado autólogo de plaquetas en conejos: estudio piloto. Rev Med Vet Zootec 64: 2431. doi: $10.15446 / \mathrm{rfm} v z . v 64 \mathrm{n} 1.65813$

7. Boswell SG, Cole BJ, Sundman EA, Karas V, Fortier LA. 2012. Plateletrich plasma: a milieu of bioactive factors. Arthroscopy 28: 429-439. doi: 10.1016/ j.arthro.2011.10.01

8. Brancato SK, Albina JE. 2011. Wound macrophages as key regulators of repair origin, phenotype, and function. Am J Pathol 178: 19-25. doi: 10.1016/ j.ajpath.2010.08.003

9. Brodland DG 1994. Fundamentals of flap and graft wound closure in cutaneous surgery. Cutis 53: 192-200.

10. Burnouf T, Goubran H, Chen T, Ou K, El-Ekiaby M, Radosevic M. 2013. Blood-derived biomaterials and platelet growth factors in regenerative medicine. Blood Rev 27: 77-89. doi: 10.1016/ j.blre.2013.02.001

11. Coll L, 2016. Skin grafts and flaps. In: Saunders R, Astifidis S, Burke J, Higgins $\mathrm{J}, \mathrm{McClinton} \mathrm{M}$ (eds). Hand and upper extremity rehabilitation. $4^{\text {th }}$ ed. St. Louis, Missouri: Elsevier. p 13-19.

12. da Costa A, Barbieri C, Mazzer N, Brito S, Thomazini J. 2007. Can therapeutic ultrasound influence the integration of skin grafts? Ultrasound Med Biol 33: 1406-1412. doi: 10.1016/ j.ultrasmedbio.2007.04.002

13. Eppley BL, Woodell JE, Higgins J. 2004. Platelet quantification and growth factor analysis from platelet-rich plasma: implications for wound healing. Plast Reconstr Surg 114: 1502-1508. doi: 10.1097/01.PRS.0000138251.07040.51 
14. Gurtner GC, Werner S, Barrandon Y, Longaker MT. 2008. Wound repair and regeneration. Nature 453: 314-321. doi:10.1038/nature07039

15. Jensen AR, Klein MB, Ver Halen JP, Wright AS, Horvath KD. 2008. Skin flaps and grafts: a primer for the national technical skills curriculum advanced tissue-handling module. J Surg Educ 65: 191-199. doi: 10.1016/j.jsurg.2008.03.004

16. João de Masi EC, Campos AC, de Mais FD, Ratti MA, Ike IS, de Mais RD. 2016. The influence of growth factors on skin wound healing in rats. Braz J Otorhinolar 82: 512-521. doi: 10.1016/j.bjorl.2015.09.011

17. Kim SJ, Kim SY, Kwon CH, Kim YK. 2007. Differential effect of FGF and PDGF on cell proliferation and migration in osteoblastic cells. Growth Factors 25: 77-86. doi: 10.1080/08977190701398977

18. Koh TJ, DiPietro LA. 2011. Inflammation and wound healing: the role of the macrophage. Expert Rev Mol Med 13-23. doi: 10.1017/S1462399411001943

19. Le Cocq H, Stanley PRW. 2011. Closing the gap: skin grafts and flaps. Surgery 29: 502-506. doi: 10.1016/ j.mpsur.2011.06.021

20. Lucas J. 2017. The physiology and biomechanics of skin flaps. Facial Plast Surg Clin N Am 25(3):303-311. doi: 10.1016/j.fsc.2017.03.003

21. Madden JW, Peacock EE. 1971. Studies on the biology of collagen during wound healing. III Dynamic metabolism of scar collagen and remodeling of dermal wounds. Ann Surg 174: 511-520.

22. Mahdavian Delavary B, van der Veer $W M$, van Egmond $M$, Niessen $F B$, Beelen RH. 2011. Macrophages in skin injury and repair. Immunobiology 216 : 753-762. doi: 10.1016/j.imbio.2011.01.001

23. Martin P, Leibovich SJ. 2005. Inflammatory cells during wound repair: the good, the bad and the ugly. Trends Biochem Sci 15: 599-607. doi: 10.1016/ j.tcb.2005.09.002
24. Meszaros A, Reichner J, Albina J. 1999. Macrophage phagocytosis of wound neutrophils. J Leukocyte Biol 65:35-42. doi: 10.1002/jlb.65.1.35

25. Moro L, Vasconcelos AC, Santos FGA, Alves CM., Nunes JES, Sampaio IBM. 2004. Determination of the minimal representative number of microscopic fields to quantify apoptosis in canine lymph nodes. Arq Bras Med Vet Zoo 56: 408-410. doi: 10.1590/S010209352004000300020

26. Pazzini J, De Nardi A, Huppes R, Gering $A$, Ferreira $M$, Silveira $C$, Luzzi M, Oliveira J. 2016. Utilização de plasma rico em plaquetas para estimulação da angiogênese em flape de padrão axial toracodorsal em coelhos (Oryctolagus cuniculus). Pesq Vet Bras 36: 108-118. doi: 10.1590/S0100736X2016000200008

27. Portou MJ, Baker D, Abraham D, Tsui J. 2015. The innate immune system, toll-like receptors and dermal wound healing: a review. Vascul Pharmacol 71: 31-36. 10.1016/ j.vph.2015.02.007

28. Reinke J, Sorg H. 2012. Wound repair and regeneration. Eur Surg Res 49: 3543. doi: 10.1159/000339613

29. Schultz, T, Cunningham K, Bailey J. 2014. Basic flap design. Oral Maxil Surg Clin 26: 277-303. doi: 10.1016/ j.coms.2014.05.001

30. Sterne GD, Fatah F. 2002. Grafts and flaps. Surgery 20: 134-138. doi: 10.1383/ surg.20.6.134.14638

31. Sun W, Sun W, Lin H, Sun W, Lin H, Xie H, Xiao Z. 2007. Collagen membranes loaded with collagen-binding human PDGF-BB accelerate wound healing in a rabbit dermal ischemic ulcer model. Growth Factors 25: 309-318. doi: 10.1080/08977190701803885

32. Trevor PB, Smith MM, Waldron DR, Hedlund CS.1992. Clinical evaluation of axial pattern skin flaps in dogs and cats: 19 cases (1981-1990). J Am Vet Med Assoc 201: 608-612. 
33. Wang B, Geng Q, Нu J, Shao J, Ruan J, Zheng J. 2016. Platelet-rich plasma reduces skin flap inflammatory cells infiltration and improves survival rates through induction of angiogenesis: an experiment in rabbits. J Plast Surg Hand Su 50: 239-245. doi: 10.3109/2000656X.2016.1159216

34. Witte MB, Barbul A. 1997. General principles of wound healing. Surg Clin N Am 77: 509-528. doi: 10.1016/S00396109(05)70566-1
35. Wong VW, Gurtner GC, Longaker MT. 2013. Wound healing: a paradigm forregeneration. Mayo Clin Proc 88: 10221031. doi: 10.1016/j.mayocp.2013.04.012

36. Xian LJ, Chowdhury SR, Bin Saim A, Idrus RB. 2015. Concentrationdependent effect of platelet-rich plasma on keratinocyte and fibroblast wound healing. Cytotherapy 17: 293-300. doi: 10.1016/j.jcyt.2014.10.005

37. Zhang X, Mosser DM. 2008 Macrophage activation by endogenous danger signals. J Pathol 214: 161-178. doi: 10.1002/path.2284 